NASA Technical Memorandum 1100674

INTERFERENCE EFFECTS ON THE HYPERSONIC, RAREFIED FLOW ABOUT A FLAT PLATE

Richard G. Wilmoth

(NASA-TE-100674) INIEEFEEEACE EFFECTS OA ILE HYPEBSCAIC, GLRERIED FLC ABCUI A FLAT

FIATE (BASA) 38 F

CSCL 20D

x $89-13730$

Unclas

G3/3401747C8

September 1988

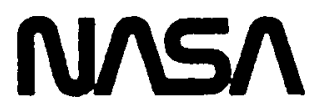

National Aeronautics and

Space Administration 
INTERFERENCE EFFECTS O:I THE HYPI RSONIC, RAREFIED

FLOW ABOUT A FLAT PI ATE

\author{
Richard G. Wilmoth \\ NASA Langley Research Center \\ Hampton, Virg! nia 23665-5225
}

\begin{abstract}
$\underline{\text { Abs tract }}$
The Direct Simulation Monte Carl', method is used to study the hypersonic, rarefied flow interference effects on a flat plate caused by nearby surfaces. Calculations focus in shock-houndary-layer and shock-1ip Interactions in hypersonic inlets. Risults art presented for geometries consisting of a flat plate with different leading-edge shapes over a flat lower wall and a blunt-edged flat plate over a 5-degree wedge. The problems simulated correspond to a typical entry flight condition of $7.5 \mathrm{~km} / \mathrm{s}$ at altitudes of 75 to $90 \mathrm{~km}$. The results show increases in predicted local heating rates for shock-boundary-layer and shock-11p interactions that are qualitatively similar to those observed experimentally at much higher densities.
\end{abstract}

Nomenclature

$\mathrm{C}_{\mathrm{H}}$ heat-transfer coefficient, $2 \mathrm{q} / \mathrm{p}_{\infty} \mathrm{U}_{\infty}{ }^{3}$

$\mathrm{C}_{\mathrm{p}} \quad$ pressure coefficient, $2 \mathrm{p} / \infty_{\infty} \mathrm{U}_{\infty}{ }^{2}$

$\mathrm{Kn}_{\infty} \quad$ freestream Knudsen number, $\lambda_{\infty} / \mathrm{R}_{\mathrm{N}}$

$\ell \quad$ characteristic dimension

$M_{\infty} \quad$ freestream Mach number

p pressure

q heat flux

$\mathrm{R}_{\mathrm{N}} \quad$ leading-edge nose radius

$\operatorname{Re}_{\infty} \quad$ Reynolds number, $\rho_{\infty} U_{\infty} l / \mu_{\infty}$ 


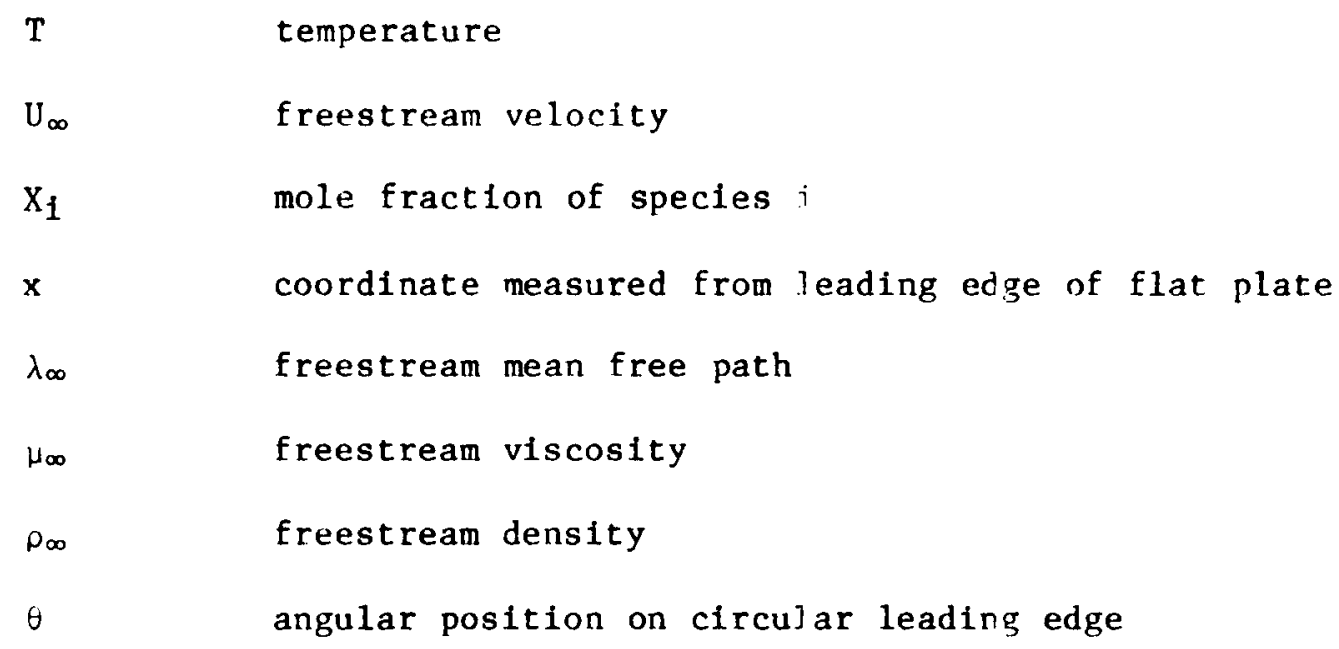

Introduction

Viscous-inviscid interactions occurring in high Mach number flight represent one of the most severe problems assoclated with hypersonic cruise and entry vehicles. The strongest interactions are usually associated with some form of shock impingement such as that occurring on the cowl lip or wall boundary layers of hypersonic inlets as illustrated in Fig. 1. These interactions can result in high local heating which may lead to component failures. An excellent review of the variety of problems that can occur along with examples of some actual failures is given by Korkegi.'

The most severe conditions for viscous-inviscid interaction problems are usually associated with the higher densities of the continuum flow regime. However, similar interactions are expected to occur at the lower densities associated with initial entry or sub-crbital maneuver conditions (typically above $70 \mathrm{~km}$ ). Although the strength of the interactions may be expected to 
be weaker in these transitional flows, localizel problems may still occur. Furthermore, even when the overall flowfield is essentially continuum, the analysis of the problem may require modifications to account for local transitional or rarefied flow effects. ${ }^{2}, 3$ The use of a purely continuumbased analysis typically leads to an overprediction of the local heating rates in such cases.

The Direct Simulation Monte Carlo (DSMC) mithod of Bird ${ }^{4}, 5$ has been used extensively to study a variety of transitional and rarefied flow problems in hypersonic flows. For the most part, these studies have focused on modeling the physics ${ }^{4-9}$ or on calculations of complex flows about simple geometries. ${ }^{10-15}$ Studies of more complex geometries have been 11mited since they require the more difficult three-dimensional codes ${ }^{16}$ or require prohibitively large computer storage and CPU time to resolve the flow around complex shapes even for two-dimensional problens. However, with the current availability of supercomputers and with recent improvaments to existing DSMC

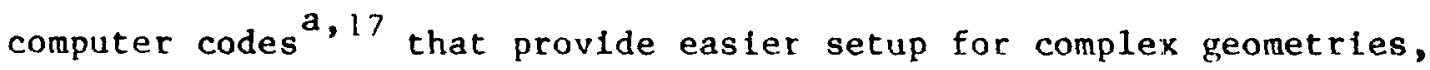
multi-surface interaction problems can be more readily studied.

The purpose of the present paper is to present initial results of a study of some of the basic interactions shown in Fig. 1 for hypersonic inlets. Although calculations are presented for specific geometries (see Fig. 2), the results are mainly intended to demonstrate the nature of the interactions at low densities and to show both the similarities and the differences in comparisons to analogous interactions in continuum flows. A flat plate was used to simulate an inlet cowl, since extensive studies have

a Bird, G. A., Private Communication, 1987. 
been made of the flow over isolated flat plates and the expected flow behavior is reasonably well understood. $12,13,1 \varepsilon-21$

The results in this paper focus on some of the basic interference effects between two parallel flat plates and on the interference caused by an oblique shock impinging on the leading edge of the plate. The calculations were performed at nominal entry-type conditions of $7.5 \mathrm{~km} / \mathrm{s}$ at an altitude of $90 \mathrm{~km}$ for the parallel flat plates and over an altitude range of 75 to $90 \mathrm{~km}$ for the shock impingement calculations.

\section{Direct Simulation Monte Carlo Method}

The DSMC method of Bird has been described extensively in the 1iterature. ${ }^{4}, 5$ The method consists of simulating a gas by some thousands of molecules whose positions, velocities, and internal states are stored and modified with time as the molecules move, collide, and undergo boundary interactions in simulated physical space. A time step is chosen such that the movement and collision processes can be assumed to be uncoupled over the duration of the step. The calculations are started with an initial state such as a vacuum or uniform equilibrinn flow. The simulation time is identified with physical time in the real flow, and all calculations are treated as unsteady. When boundary conditions appropriate to steady flow are imposed, the solution is the asymptotic limit of the unsteady flow.

A physical space computational cell networic is required only to facllitate the choice of collision pairs and the sampling of flow properties. The cells may be divided into subcells for selection of collision pairs to better simulate the nearest neighbor collisions in regions of high vorticity. The collisions are simulated using the "variable hard sphere" 
(VHS) molecular model with modifications to account for rotational and vibrational states in diatomic or poly.tomic gasies. 5

\section{Geometries and Conditions for the Calculations}

Two basic two-dimensional geometries, shown in Ffg. 2, were studied. Figure 2(a) shows a sharp-edged flat plate parallel to a flat lower wall. This geometry was used to study the in:eractions between the lower wall and the flat plate with different boundary conditions imposed on the lower wall. The effects of the leading-edge shapes shown in Fig. 2(c) were also computed. A set of calculations was also made with the lower wall representing a 5-degree wedge ramp (F1.,. 2(b)) to produce an ob1tque shock that impinged on the leading edge of the plate. For these calculations, on1y the blunt (circular) leading edge was used.

Calculations for the flat lower wall were performed only for the $90-\mathrm{km}$ condition using the freestream values given in Table $l$. Calculations for the 5-degree wedge lower wall were made at all four altitudes given in Table 1. The freestream Mach number was 27.2 in all cases. The species mole fractions at altitudes below $90 \mathrm{~km}$ were held constant at values appropriate to $90 \mathrm{~km}$ using the tables of Ref. 22. Thus the chemical species simulation is realistic only at the $90-\mathrm{km}$ condition. Some of the flow parameters, expressed in terms of the leading-edge nose radius, are given in Table 2.

The computational domains and typical cell grids for the two geometries are shown in Fig. 3. The heavy solld lines represent region boundaries within which the time step and the molecule welghting factor (relating the number of computational molecules to the number of physical molecules) are constant. For the circular leading-edge cases, cells were clustered around the leading edge. The cell size was reduced at the lower altitudes in order 
to minimize the flow gradients across the cell in a direction normal to the leading-edge surface.

For all calculations, the wall temperature of the flat plate was assumed to be constant at $1000 \mathrm{~K}$, and gas-surface collisions were assumed to be diffuse with full thermal accommodation. The same wall conditions were generally used for the lower wall except for a few cases with the flat lower wall in which the boundary was treated as specular or as a freestream boundary.

\section{Results and Discussion}

\section{Isolated Flat Plate Predictions}

To establish the undisturbed nature of the isolated flat plate flow, calculations were made at the $90-\mathrm{km}$ conditions with each of the leading-edge shapes and with the lower wall treated as a freestream boundary. The pressure and heat transfer distributions along the upper surface of the plate for these cases are shown in Fig. 4. At $90 \mathrm{~km}$, the length of the plate corresponds to about $25 \lambda_{\infty}$, and the results are typlcal of transitional flow behavior. ${ }^{13, \mathrm{~b}}$ For the -20 degree wedge, the upper surface is flat, and the results are nearly identical to the zero thickness case. The slight differences between the -20 degree and zero-thlckness results are attributed to the fact that molecules striking the lower surface of the leading edge have a fairly high probability of reaching the upper surface through gas-gas collisions at this Knudsen number. With the +20 degree wedge and circular leading edges, the pressure and heat-transfer coefficients are highest near the leading edge and decrease downstruam, approaching the zero thickness

\footnotetext{
Boss, J. N., Unpublished Results, 1987.
} 
results near the end of the plate. While the +20 degree wedge shows higher pressures and heat transfer in Fig. 4 than the circular leading edge, results are shown only for the flat portion of the plate downstream of the leading edge. The peak stagnation values on the leading edge itself are actually higher for the clrcular leading edge. In all cases, the pressure and heattransfer coefficients are much higher than the calculated free-molecular values of 0.003 for $C_{p}$ and 0.01 for $C_{H}$ at these conditions. The trends shown in Fig. 4 are qualitatively similar to those expected in continuum flows. Interactions with Flat Lower Wall

The pressure and heat-transfer distributions along the lower surface of the plate with the blunt leading edge are shown in Fig. 5 for different lower wall boundary conditions. The freestream lower boundary condition represents the isolated or undisturbed flat plate. A specular lower boundary is equivalent to a plane of symmetry, and the geometry for this calculation is analogous to the entrance of a two-dimensional channel. whose height is twice the distance between the plate and the symmetry plane. The results show a gradual rise in the pressure and heat transfer due to the growth of the boundary layer along the lower surface of the (upper) flat plate.

With a diffuse lower wall, the grometry becomes similar to an inlet with a flat ramp, and the results show a more complex behavior. The pressures are much higher than the undisturbed predictions, and the distribution shows a steep rise starting at about $0.16 \mathrm{~m}$ (approximately $7 \lambda_{\infty}$ ). The pressure reaches a maximum at about $0.32 \mathrm{~m}$ and then decreases continuously to the exit of the channel. The heat-transfer distribution exhibits a maximum near the leading edge and decreases continuously downstream. However, there does appear to be an inflection in the heat-transfer distribution near the location of the pressure rise. 
The above behavior is caused by the interaction of a diffuse bow shock generated by the leading edge which sirlkes and 1 s reflected.from the lower wall. This reflection is evident in the pressure distribution along the specular lower wall shown in F1g. 6. Significant differences in the location of the reflected bow shock are seen for different leading-edge shapes. These differences are probably more pronounced at the $90-\mathrm{km}$ conditions than might be expected at lower altitudes becausis of the large curvature and thlckness of the shock, which is roughly the sane order of magnitude as the channel height.

For the diffuse lower wall (see $F i g .7$ ), the differences in the Interaction for different leading-edge shapes are not as pronounced. Also, the relative strength of the interaction (In terms of the ratio of pressures across the interaction region) is reduced by the presence of the lower wall boundary layer (although the overall pressures are higher due to boundary-layer displacement effects). The results shown here are qualitatively similar to the experimental data of Kaufman and Johnson ${ }^{23}$ for weak shocks incldent on laminar boundary layers. Although the experiments were conducted at much higher densities $\left(\operatorname{Re}_{\infty} \approx 10^{6}\right.$ per meter) and at a lower Mach number $\left(M_{\infty}=8\right)$, a reasonable compartson can be made based on the peak pressure rise. For the results in Fig. 7, the ratio of peak to upstream pressures is about 8 to 10, while the ratio of the peak to upstream heating rates is about 2.5 to 3.0 . Based on the correlation of heating-rate amplification to peak-pressure amplification given in Ref. 23, the heating-rate amplification at the same pressure amplification would be roughly 15 to 20 at the Reynolds numbers of the experiment. The weaker interaction for the present calculations is perhaps not too surprising, since the shock is much more diffuse at the lower densities. 
The pressure and heat-transfer distributions downstream of the shock Interaction on the diffuse lower wall shows significant streamwise gradients extending to the exit of the internal region. Since the boundary layers are quite thick relative to the channel helght, a significant portion of the Internal flow is subsonic. Therefore, it is quite likely that the location of the exit and the boundary conditions imposed on the exit plane may have a significant influence on the shock-boundary layer interaction. Because of this possible influence, the post-shock flow quantities may not be representative of those for isolated shock reflections from laminar boundary 1ayers.

Interaction with 5-Degree Wedge Lower Wall

For the calculations with the 5-degree wedge lower wall, the main Interest in this study is on the interaction of the oblique shock generated by the wedge with the leading edge of the flat plate. Therefore, the following results focus on the surface properties on the blunt lip of the plate.

The pressure and heat-transfer distributions around the leading edge of an 1solated flat plate are shown in Fig. 8 for several altitudes. The stagnation pressure coefficient shows a slight decrease with decreasing altitude, whereas the stagnation heat-transfer coefficient decreases somewhat more rapidly. (It should be noted that although $C_{H}$ decreases with decreasing altitude, the absolute heating rate actually increases.) The results shown here are in reasonable agreement with the predictions of Cuda and Moss ${ }^{10}$ that were obtained under similar freestream conditions but with a larger nose radius. A correlation of the stagnation heat-transfer predictions for the present calculations with those of Cuda and Moss is presented later in this paper. 
As a result of the viscous shock layer caused by the 5-degree wedge, the leading edge of the flat plate is subjected to higher temperatures and densities. The qualitative features of the flowfield are demonstrated by the gray-shaded contours shown in Fig. 9, where the darker regions represent higher temperatures and densities. The variation in the extent of the overall thermal environment with altitude is clearly shown by the temperature contours, while the thickness and location of the oblique wedge shock are reasonably evident in the density contours. At $90 \mathrm{~km}$, the distance from the start of the 5-degree wedge to the leading edge of the flat plate corresponds to about $50 \lambda_{\infty}$. At $75 \mathrm{~km}$, this distance corresponds to about $800 \lambda_{\infty}$. At $90 \mathrm{~km}$, the shock is very thick relative to the leading-edge radius, and the peak density in the undisturbed shock is about twice the freestream value. At $75 \mathrm{~km}$, the shock is more clearly defined with a peak density that is about four times the freestream density.

It should be noted that the gradients in flow quantities across the shock are probably not adequately resolved at the lower altitudes because of the relatively coarse grid used for sampling. Although an attempt was made to accurately simulate the collisions in the shock by increasing the number of subcells at the lower altitudes, the average flow properties are always determined from the total sample within a cell. Since the gray contours are produced by filling each cell with a level-of-gray halftone shading that is proportional to the flow quantity, the shock may appear to be artificially smeared in these contours. However, the cell size used near the leading-edge surface was adequate to give reasonably accurate predictions of surface heating as determined by a cell-size sensitivity study.

The pressure and heating-rate distributions around the plate leading edge with the 5-degree wedge shock are shown in Fig. 10. Both quantities 
have been nondimensfonalized by the peak stagnation values for the isolated leading edge at the corresponding altitude. Therefore, peak values greater than one indicate an amplification of the pressure or heating rate resulting from Impingement of the shock. At 90 and $85 \mathrm{~km}$, there ts little effect of the shock, while the $80-$ and $75-\mathrm{km}$ results show significant amplification of both pressure and heating rate in the stagnation region.

A comparison of the heat-transfer coefficients with the 5-degree wedge with those for the isolated leading erge is given in Fig. 11 as a function of the product of the freestream density and the leading-edge radius. The solid line is taken from the results of Cuda and Moss, ${ }^{10}$ and the present results correlate well for isolated blunt leading edges. The impingement of the wedge shock causes the heat-transfer coefficient to increase significantly with increasing density. Since the actual heating rate is proportional to the product of $\mathrm{C}_{\mathrm{H}}$ and the freestream density, the increase in heating is quite significant.

Shock Impingement effects on circular leading edges have been studied extensively for hypersonic flows at much higher densities than the present study. The works of Edney, ${ }^{24}$ Johnson and Kaufman, 25 and more recently Wieting and Holden ${ }^{26}$ describe in detail the nature of the interaction at continuum flow conditions. Although a direct comparison of the flow details from the present DSMC calculations with those given in these references is inappropriate, a qualitative comparison of the correlation of heating-rate amplification with pressure amplification may be appropriate. Using such a correlation, a comparison of the DSMC results with the shock-boundary-layer interaction data of Kaufman and Johnson ${ }^{23}$ and the shock-lip Interaction data of Wieting and Holden ${ }^{26}$ is given in Fig. 12. Although no direct conclusions should be drawn from this comparison, the interaction effects predicted by 
the DSMC method do show similar trends to those for shock interactions with laminar boundary layers. It also appears that the DSMC results adequately represent the shock-1ip interactions that might be expected at the lower densities. Further DSMC calculations at the higher densitites and/or experimenta1 measurements at the lower densities are needed.

\section{Concluding Remarks}

This initial DSMC study of interference effects on the hypersonic, rarefied flow about flat plates has focused on viscous-inviscid interactions relevant to inlet-type geometries. The results have been interpreted from somewhat of a continuum viewpoint. However, for the flight conditions presented, the distinction between viscous and inviscid regions is difficult at best. Therefore, the DSMC results need to be examined in more detall to better understand the physics involved in "viscous-inviscid" interactions at low densities.

The geometries studied and the boundary conditions used do not necessarily represent realistic hypersonic vehicle problems. This is particularly true for the Internal flow simulations where the mass flow rate depends strongly on the internal geometry and exit boundary conditions. The physical scale of the geometry is also important, and calculations for much higher Reynolds numbers would be useful. However, the DSMC method is not currently practical for very large velicles at the high Reynolds numbers. Therefore, methods which can combine ihe computational capabilities of the DSMC method with more conventional coutinuum methods are needed.

In spite of the limitations mentioned, the results of this initial study have demonstrated the usefulness of the DSMC method for the analysis of complex Interaction problems such as those present in hypersonic inlets. The 
results show qualitative trends that appear to be similar to those given by avallable experimental data.

\section{Acknowledgements}

The author wishes to express his apprectation to G. A. Bird, J. N. Moss, and E. V. Zoby for many helpful discussions.

\section{$\underline{\text { References }}$}

${ }^{1}$ Korkegi, R. H., "Survey of Viscous Interactions Associated with High Mach Number Flight," AlAA Journal, Vol. 9, No. 5, May 1971, pp. 771-784.

2Moss, J. N., "Direct Simulation of Hypersonic Transitional Flow," Rarefled Gas Dynamics, edited by V. Boffi and C. Cercignani, Vol. 1, B. G. Teubner, Stuttgart, 1986, pp. 384-399.

${ }^{3}$ Gupta, R. N. and Simmonds, A. L., "Hypersonic Low-Density Solutions of the Navier-Stokes Equations with Chemical Nonequilibrium and Multicomponent Surface Slip," AIAA Paper 86-1349, June 1986.

${ }^{4}$ BIrd, G. A., Molecular Gas Dynamics, Clarendon Press, Oxford, 1976. ${ }^{5}$ Bird, G. A., "Monte-Carlo Simulation in an Engineering Context," AIAA Progress in Astronautics and Aeronautics: Rarefied Gas Dynamics, edited by Sam S. Fisher, Vol. 74, Part 1, 1981, pp. 239-255.

${ }^{6}$ Bird, G. A., "Direct Stmulation of Typical AOTV Entry Flows," AIAA Paper 86-1310, June 1986.

${ }^{7}$ Bird, G. A., "Nonequilibrium Radiation During Re-Entry at $10 \mathrm{~km} / \mathrm{s}, "$ AIAA Paper 87-1543, June 1987.

${ }^{8}$ Bird, G. A., "Direct Simulation of Gas Flows at the Molecular Leve1," Communications in Applied Numerical Methods, Vol. 4, No. 2, March-April 1988, pp. $165-172$. 
${ }^{9}$ Bird, G. A., "Thermal and Pressure Diffusion Effects in High Altitude Flows," AIAA Paper 88-2732, July 1988.

${ }^{10}$ Cuda, V., Jr., and Moss, J. N., "Direct Simulation of Hypersonic Flows Over Blunt Slender Bodies," AIAA Paper 86-1348, June 1986.

${ }^{11}$ Dogra, V. K., Moss, J. N., and Simmonds, A. L., "Direct Simulation of Aerothermal Loads for an Aeroassist Flight Experiment Vehicle," AIAA Paper 87-1546, June 1987 .

${ }^{12}$ Harvey, J. K., "Direct Simulation Monte Carlo Method and Comparison with Experiment," AIAA Progess in Astronautics and Aeronautics:

Thermophysical Aspects of Re-Entry Flows, edited by J. N. Moss and C. D. Scott, Vol. 103, 1986, pp. 25-43.

13 Hermina, W. L., "Monte Carlo Simulation of Rarefied Flow Along a Flat Plate," AIAA Paper 87-1547, June 1987.

14Moss, J. N. and Bird, G. A., "Monte Carlo Simulations in Support of the Shuttle Upper Atmospheric Mass Spectrometer Experiment," AIAA Paper 85-0968, June 1985.

15Moss, J. N, Cuda, V., Jr., and Simmonds, A. L., "Nonequilibrium Effects for Hypersonic Transitlonal Flows," AIAA Paper 87-0404, January 1987.

${ }^{16}$ Celenligil, M. C., Bird, G. A., and Moss, J. N., "Direct Simulation of Three-Dimensional Hypersonic Flow About Intersecting Blunt Wedges," AIAA Paper 88-0463, January 1988.

${ }^{1701 y n i c k, ~ D . ~ P ., ~ M o s s, ~ J . ~ N ., ~ a n d ~ H a s s a n, ~ H . ~ A ., ~ " G r i d ~ G e n e r a t i o n ~ a n d ~}$ Adaptation for the Direct Simulation Monte Carlo Method," AIAA Paper 88-2734, July 1988 . 
${ }^{18}$ Becker, M. and Boylan, D. E., "Experimental Flow Field Investigations Near the Sharp Leading Edge of a Cooled Flat Plate in a Hypervelocity, Low-Density Flow," Rarefied Gas Dynamics, edited by C. L. Brundin, Vol. II, Academic Press, 1967, pp. 993-1014.

19 Becker, M., Robben, F., and Cattolica, R., "Velocity Distribution Functions Near the Leading Edge of a Flat Plate," AIAA Journal, Vo1. 12, No. 9, September 1974, pp. 1247-1253.

20 Hurlbut, F. C., "Sensitivity of Hypersonic Flow Over a Flat Plate to Wall/Gas Interaction Models Using DSMC," AIAA Paper 87-1545, June 1987.

${ }^{21}$ Nagamatsu, H. T. and Sheer, R. E., Jr., "Heat Transfer on a Flat Plate In Continuum to Rarefied Hypersonic Flows at Mach 19.2 and 25.4," AIAA Progress in Astronautics and Aeronautics: Thermophysical Aspects of Re-Entry Flows, edited by J. N. Moss and C. D. Scott, Vol. 103, 1986, pp. 60-78. 22U. S. Standard Atmosphere, 1976.

${ }^{23}$ Kaufman, L. G. II, and Johnson, C. B., "Weak Incident Shock Interactions with Mach 8 Laminar Boundary Layers," NASA TN D-7835, December 1974.

${ }^{24}$ Edney, B. E., "Effects of Shock Impingement on the Heat Transfer Around Blunt Bodies," AIAA Journal, Vol. 6. No. 1, January 1968, pp. 15-21.

25 Johnson, C. B. and Kaufman, Louis G. II, "Interference Heating from Interactions of Shock Waves with Turbulent Boundary Layers at Mach 6," NASA TN D-7649, 1974.

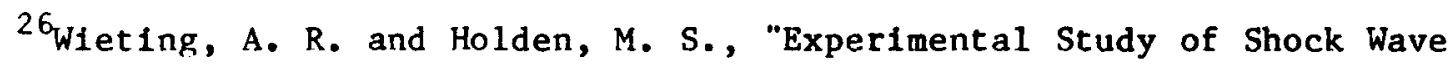
Interference Heating on a Cylindrical Leading Edge at Mach 6 and 8," AIAA Paper 87-1511, June 1987. 
Table 1. Freestrean conditions.

\begin{tabular}{|c|c|c|c|c|c|c|c|c|}
\hline \multirow{2}{*}{$\begin{array}{l}\text { Alt thude, } \\
\mathrm{km}\end{array}$} & \multirow{2}{*}{$\begin{array}{l}\text { Density, } \\
\mathrm{kg} / \mathrm{m}^{3}\end{array}$} & \multirow{2}{*}{$\begin{array}{l}U_{\infty}, \\
k m / s\end{array}$} & \multirow{2}{*}{$\begin{array}{c}\mathrm{T}_{\infty}, \\
\mathrm{K}\end{array}$} & \multicolumn{3}{|c|}{ Mole Fractions* } & \multirow{2}{*}{$\operatorname{Re}_{\mathrm{m}^{-1}} \ell$} & \multirow{2}{*}{$\underset{\infty}{\lambda_{\infty}}$} \\
\hline & & & & $\mathrm{x}_{2}$ & $\mathrm{x}_{\mathrm{N}_{2}}$ & $x_{0}$ & & \\
\hline $\begin{array}{l}90 \\
85 \\
80 \\
75\end{array}$ & $\begin{array}{l}3.4 \times 10^{-6} \\
8.2 \times 10^{-6} \\
1.8 \times 10^{-5} \\
4.0 \times 10^{-5}\end{array}$ & $\begin{array}{l}7.5 \\
7.5 \\
7.5 \\
7.5\end{array}$ & $\begin{array}{l}188 \\
188 \\
188 \\
188\end{array}$ & $\begin{array}{l}0.209 \\
0.209 \\
0.209 \\
0.209\end{array}$ & $\begin{array}{l}0.788 \\
0.788 \\
0.788 \\
0.788\end{array}$ & $\begin{array}{l}0.003 \\
0.003 \\
0.003 \\
0.003\end{array}$ & $\begin{array}{l}2.0 \times 10^{3} \\
4.9 \times 10^{3} \\
1.0 \times 10^{4} \\
4.3 \times 10^{4}\end{array}$ & $\begin{array}{l}2.4 \times 10^{-2} \\
9.9 \times 10^{-3} \\
4.4 \times 10^{-3} \\
2.2 \times 10^{-3}\end{array}$ \\
\hline
\end{tabular}

*Held constant at values appropriate for $90 \mathrm{~km}$.

Table 2. Parameters based on nose radius of blunt-edged flat

plate.

$\left[\mathrm{R}_{\mathrm{N}}=0.005 \mathrm{~m}\right]$

\begin{tabular}{crc}
\hline $\begin{array}{c}\text { Altitude, } \\
\mathbf{k m}\end{array}$ & $\operatorname{Re}_{\infty}$ & $\mathrm{Kn}_{\infty}$ \\
\hline 90 & 10 & 4.74 \\
85 & 24 & 1.98 \\
80 & 52 & 0.88 \\
75 & 109 & 0.41 \\
\hline
\end{tabular}


Hypersonic

Flow
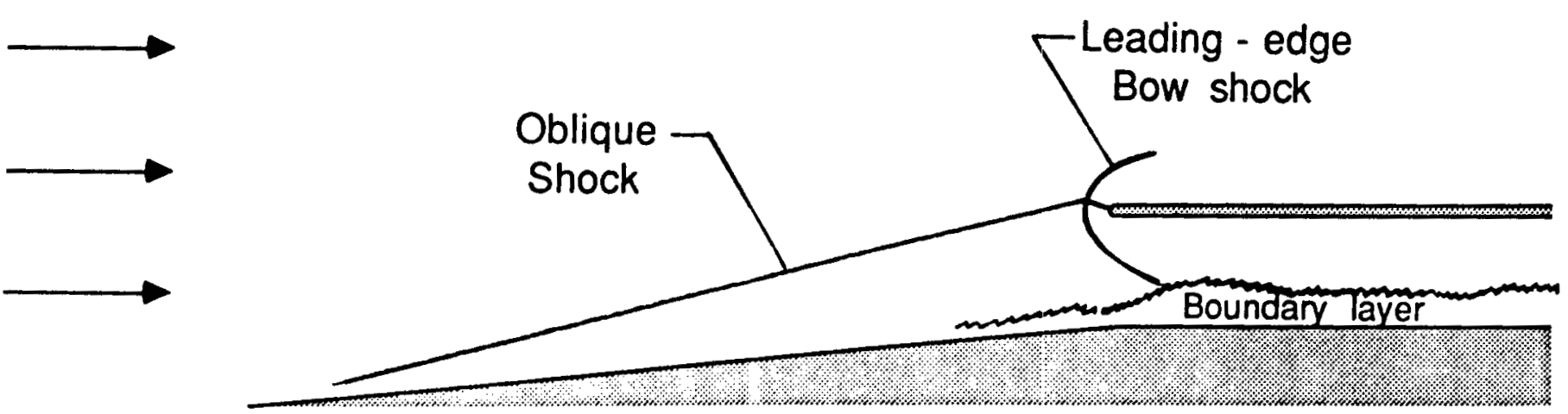

Fig. I Typical shock interactions in hypersonic inlets. 


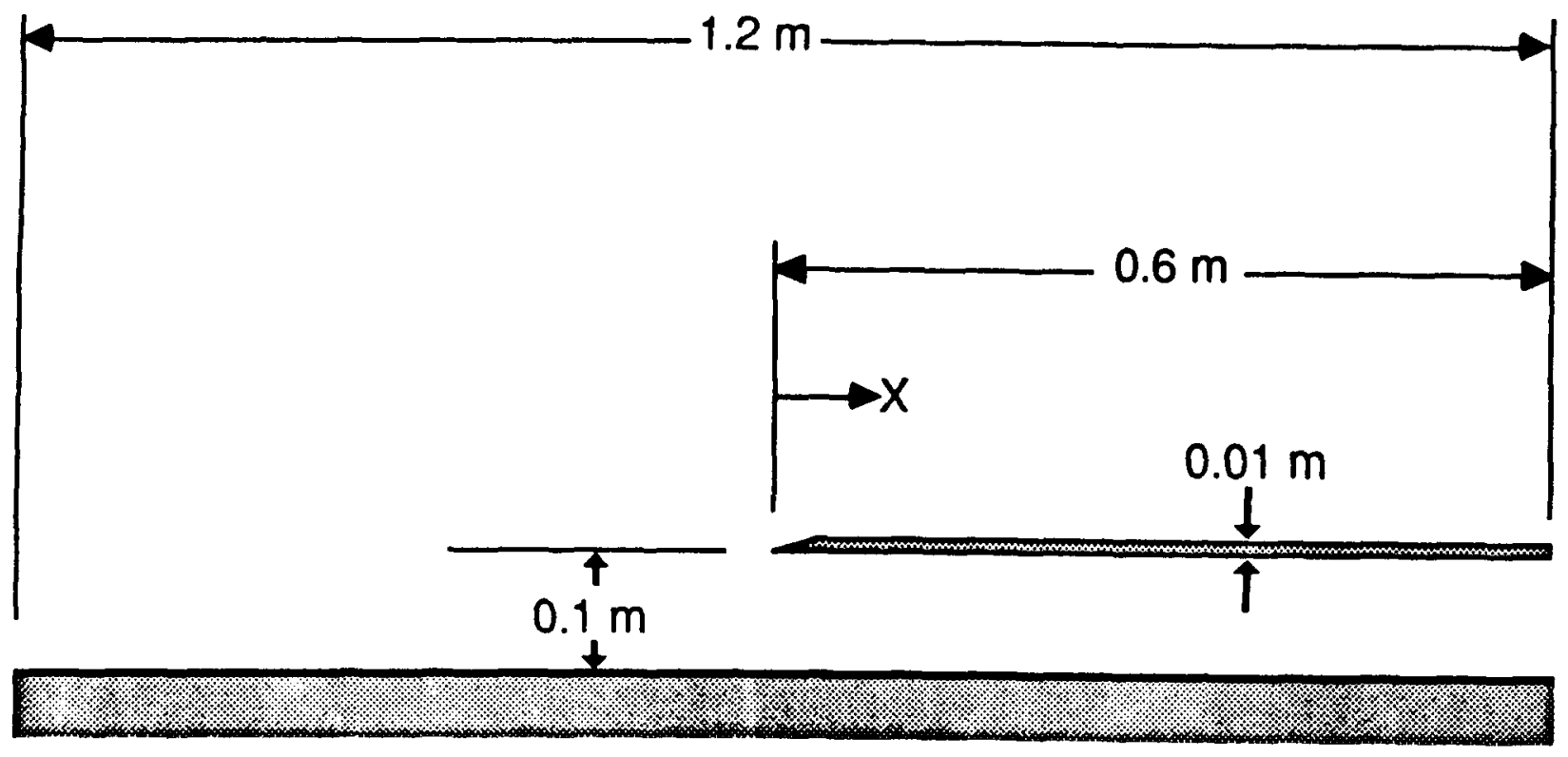

(a) Sharp-edged plate over flat lower wall.

Fig. 2 Geometries used for the calculations. 


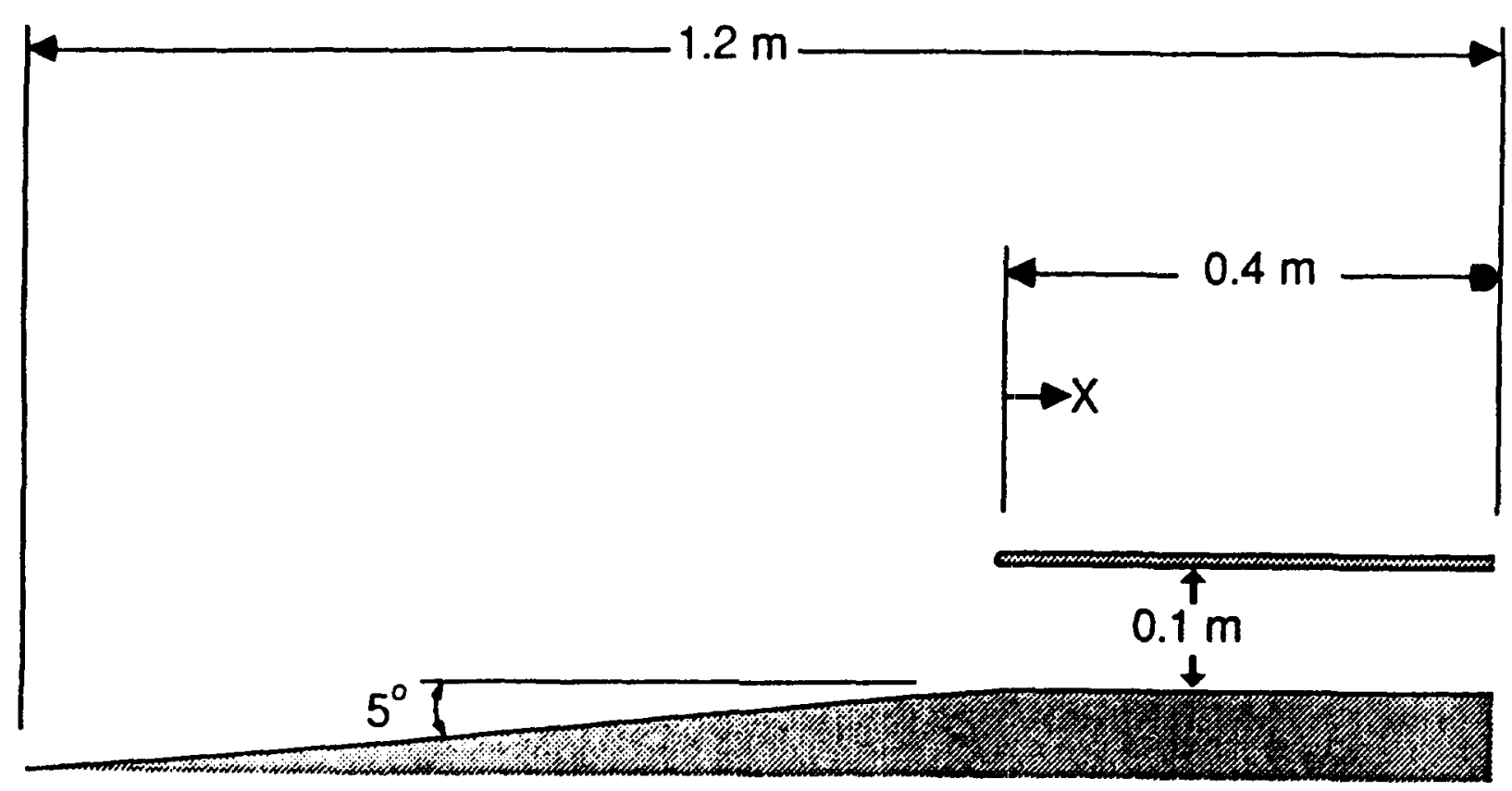

(b) Blunt-edged plate over 5-degree wedge.

Fig. 2 Continued. 


\section{Zero thickness}

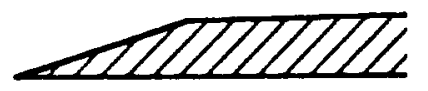

$+20^{\circ}$ wedge

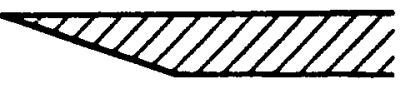

$-20^{\circ}$ wedge

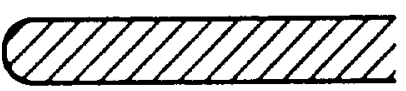

Circular (Blunt)

(c) Leading-edge shapes on flat plate.

Fig. 2 Concluded. 

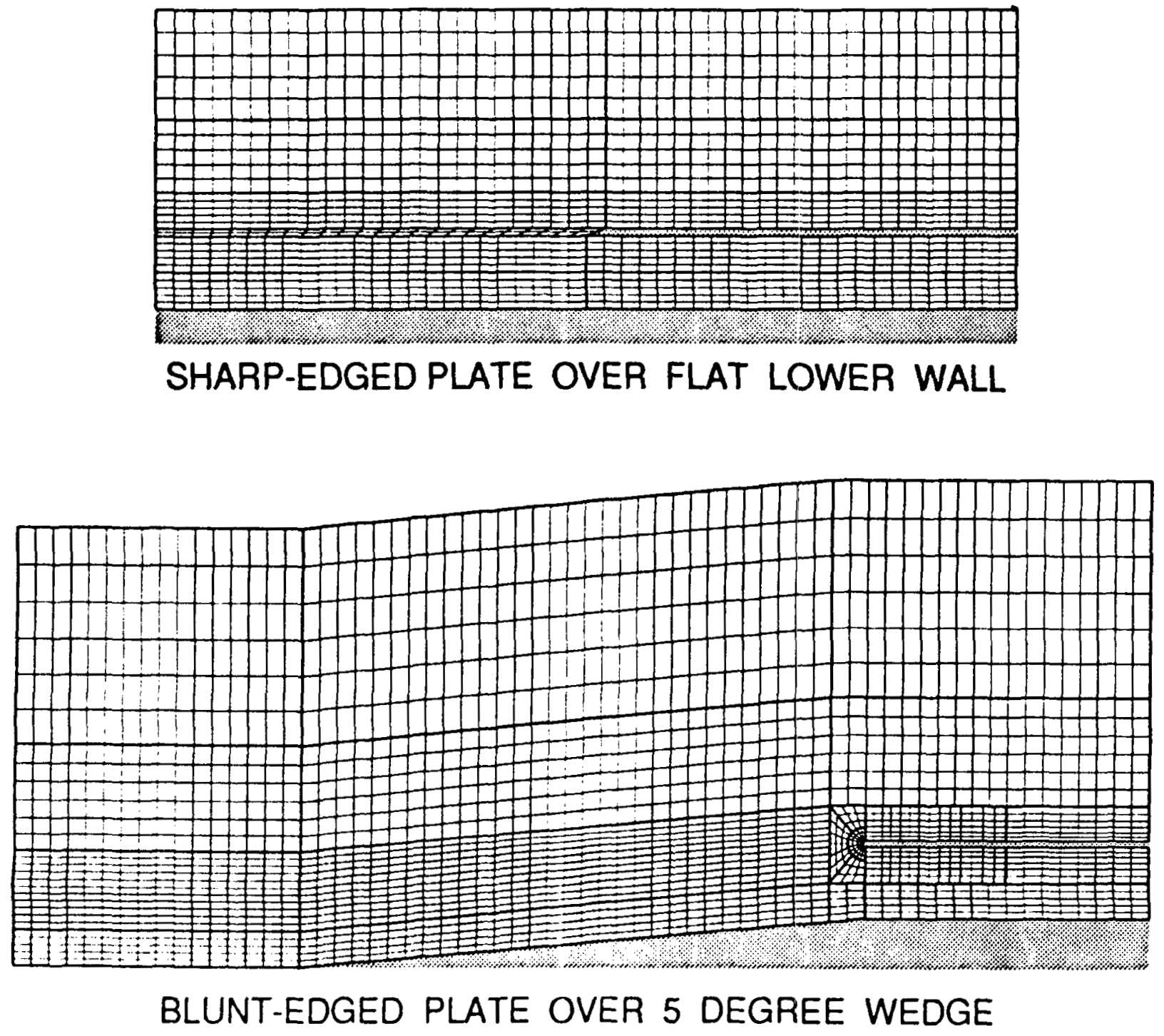

Fig. 3 Typical grids for DSMC calculations. 


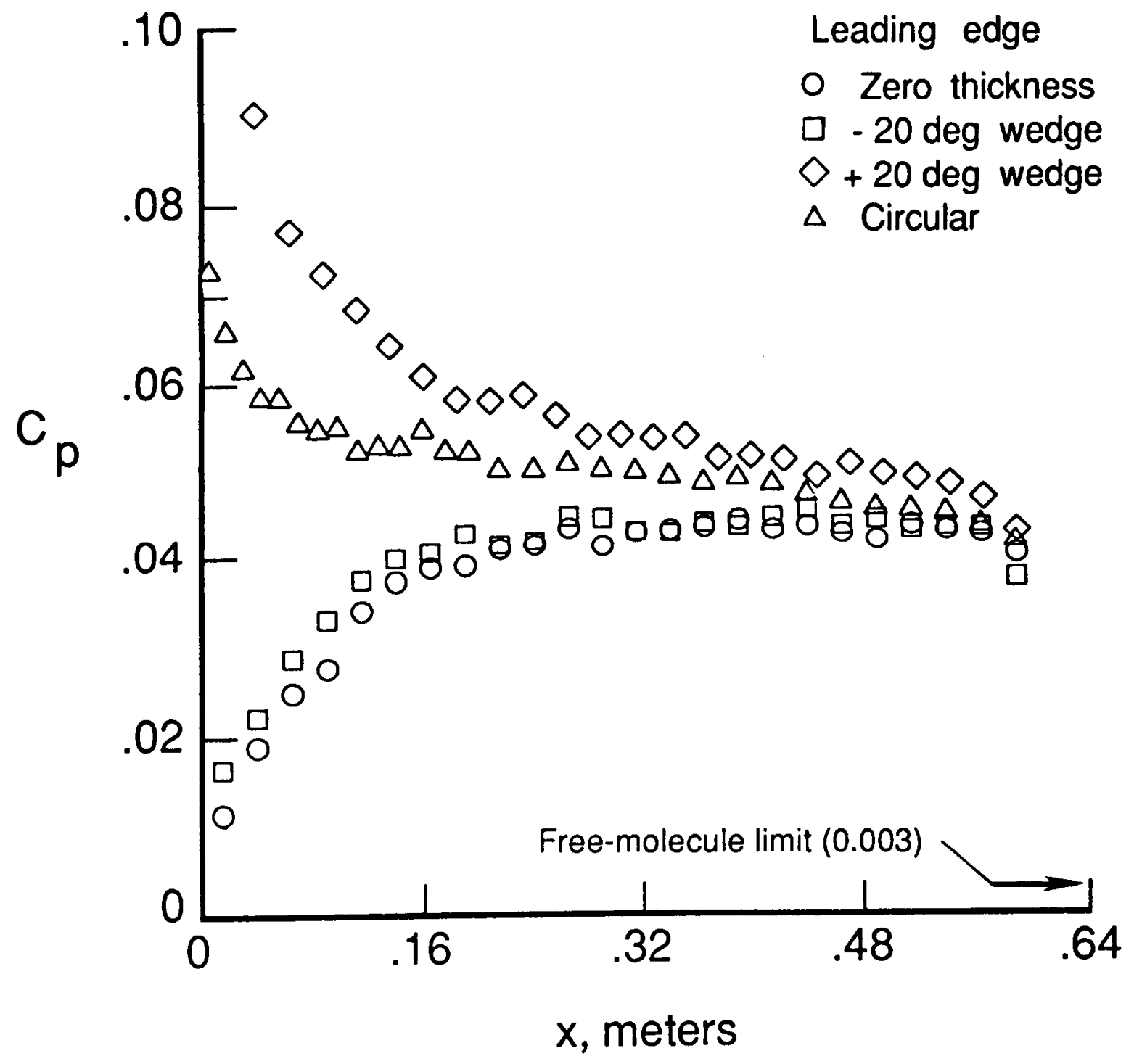

(a) Pressure distributions.

Fig. 4 Effect of leading-edge shape on pressure and heat transfer along upper surface of 1solated flat plate. (Altitude $=90 \mathrm{~km}$ ) 


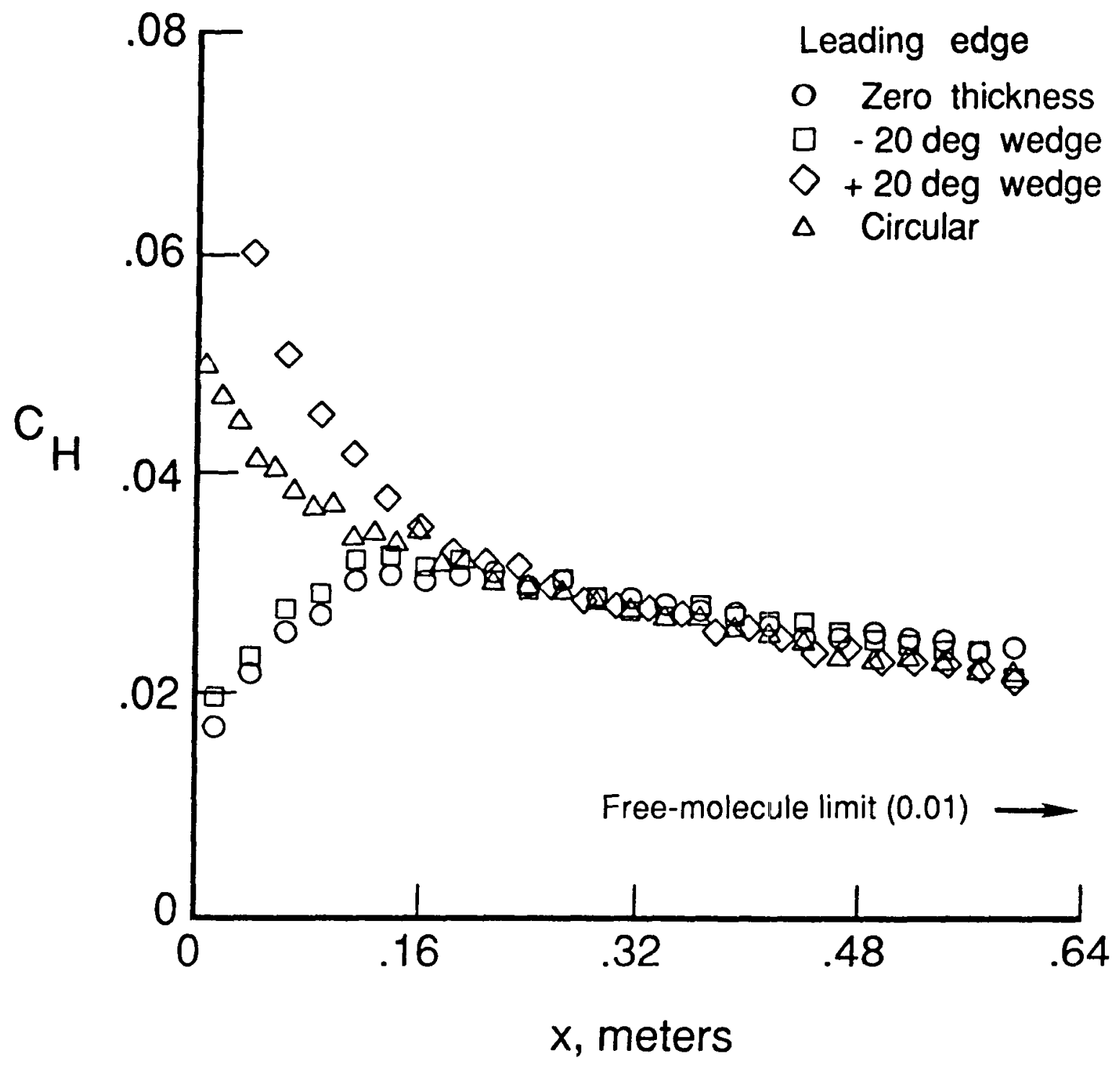

(b) Heat transfer distributions.

Fig. 4 Concluded. 


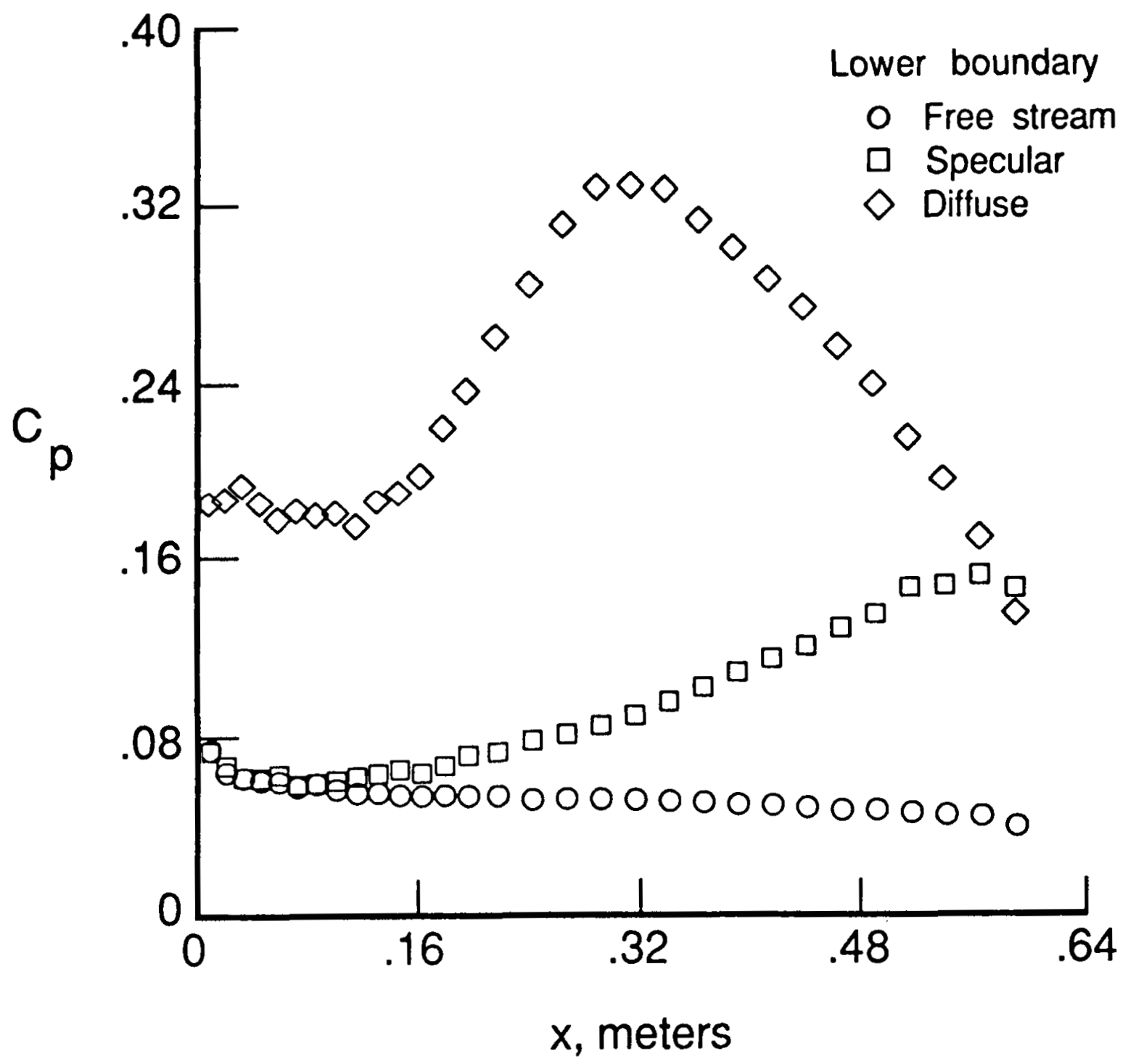

(a) Pressure distributions.

Fig. 5 Effect of lower wall bounclary on pressure and heat transfer along lower surface of flat plate. (Altitisde $=90 \mathrm{~km}$ ) 


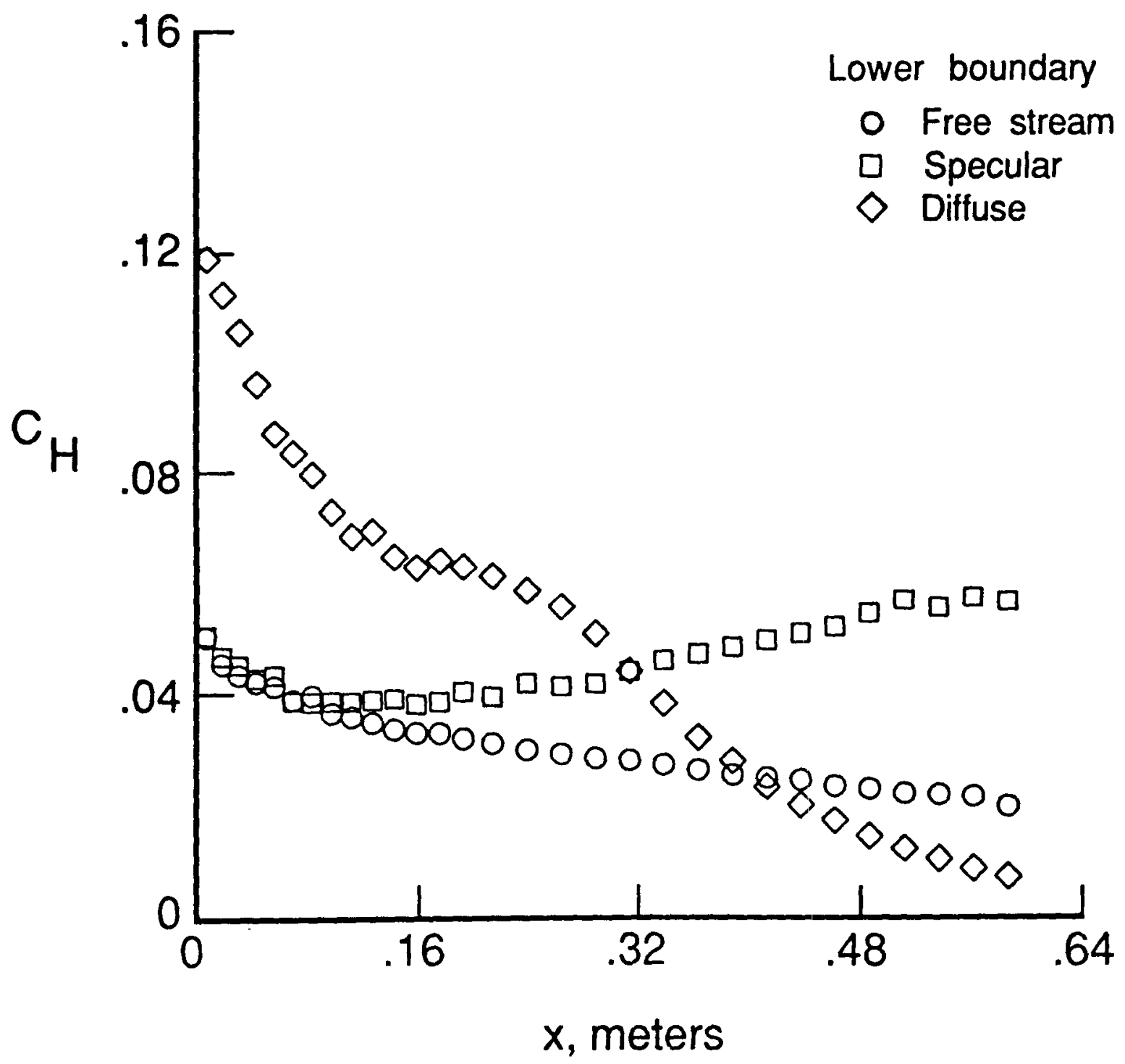

(b) Heat transfer distributions.

Fig. 5 Concluded. 


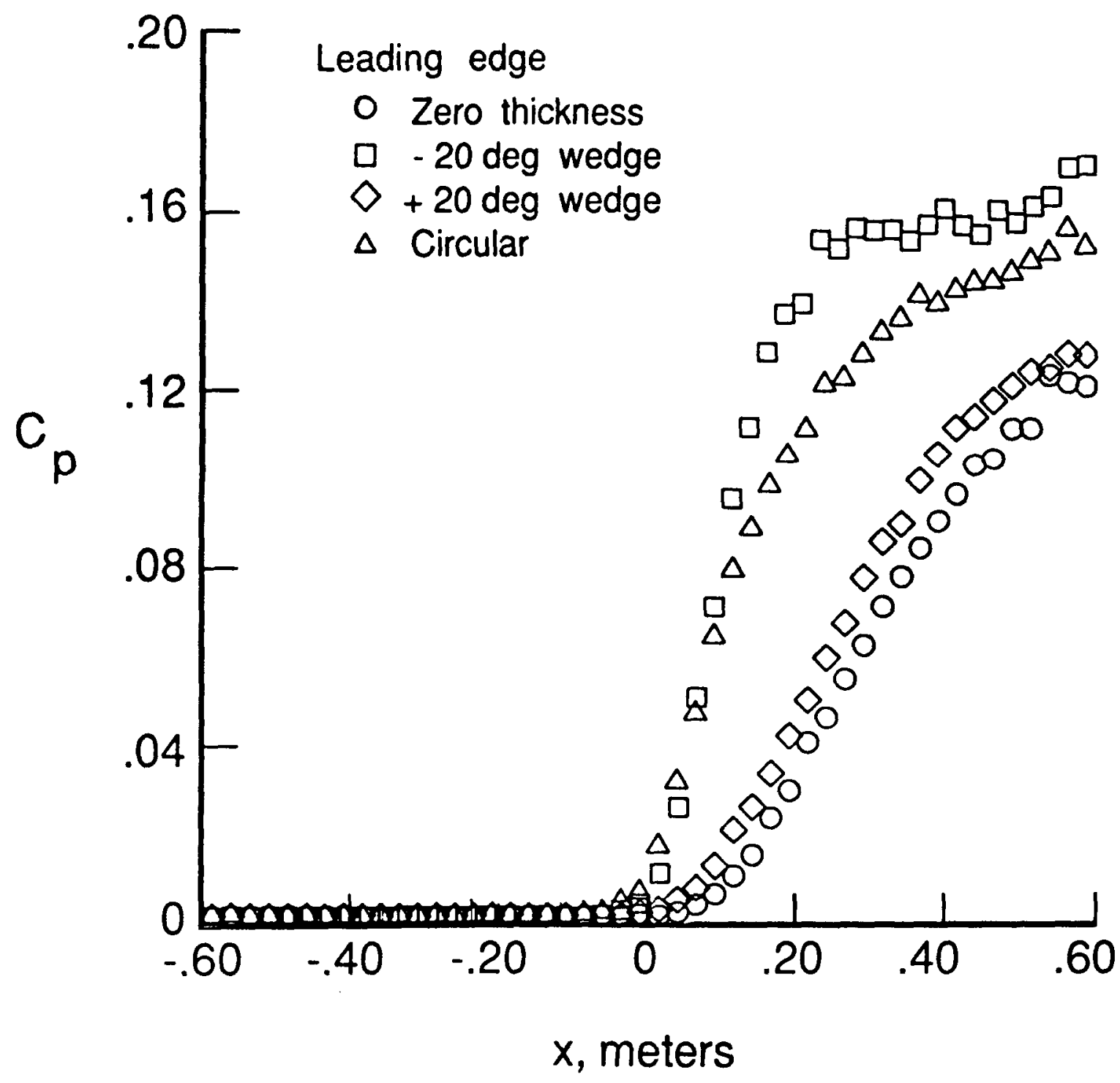

F1g. 6 Interaction of leading-edge shock with a specular lower wall boundary. (Altltude $=90 \mathrm{~km}$ ) 


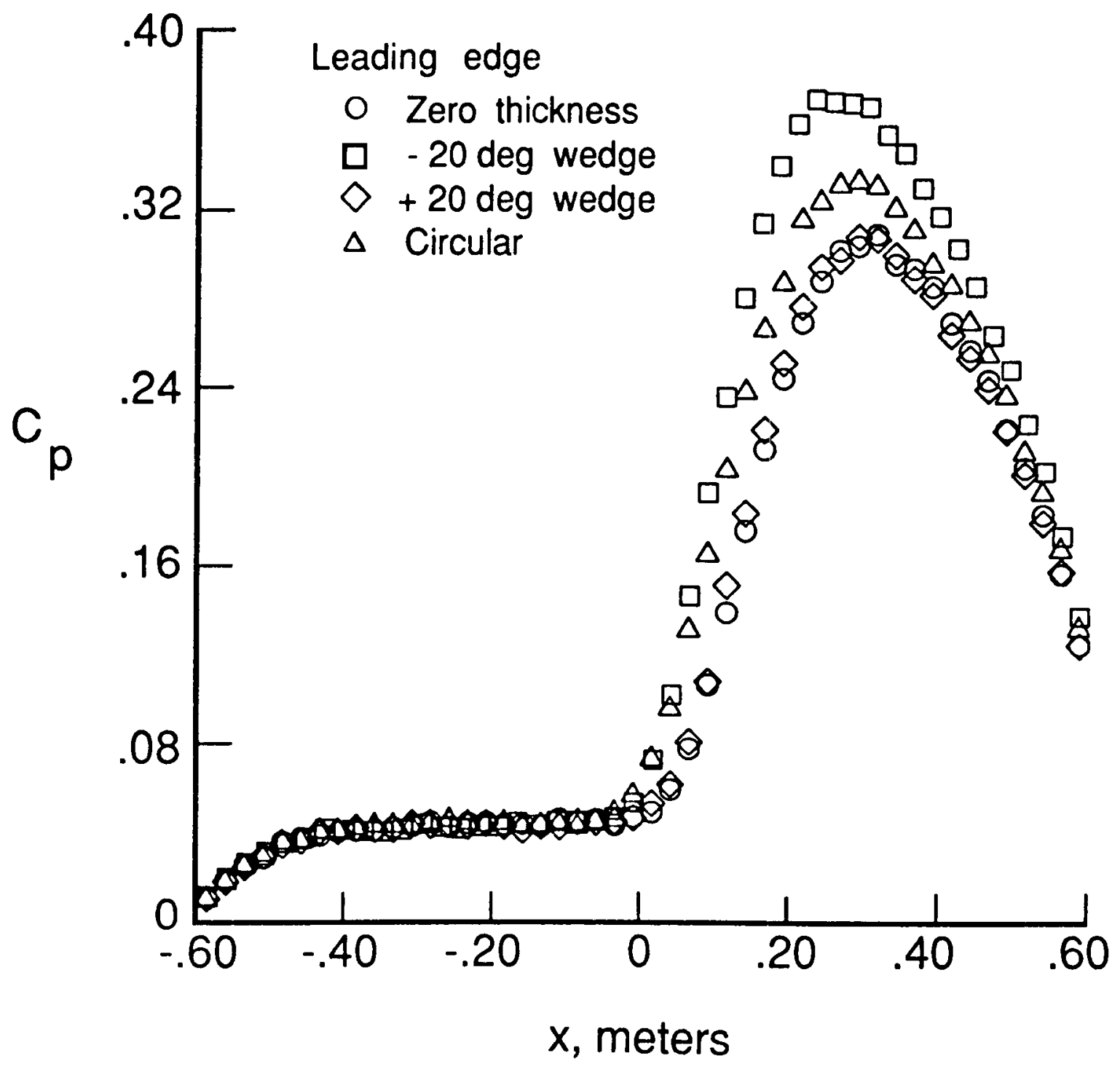

(a) Pressure distributions.

F1g. 7 Interaction of leading-edge shock with a diffuse lower wall boundary. (Altitude $=90 \mathrm{~km}$ ) 


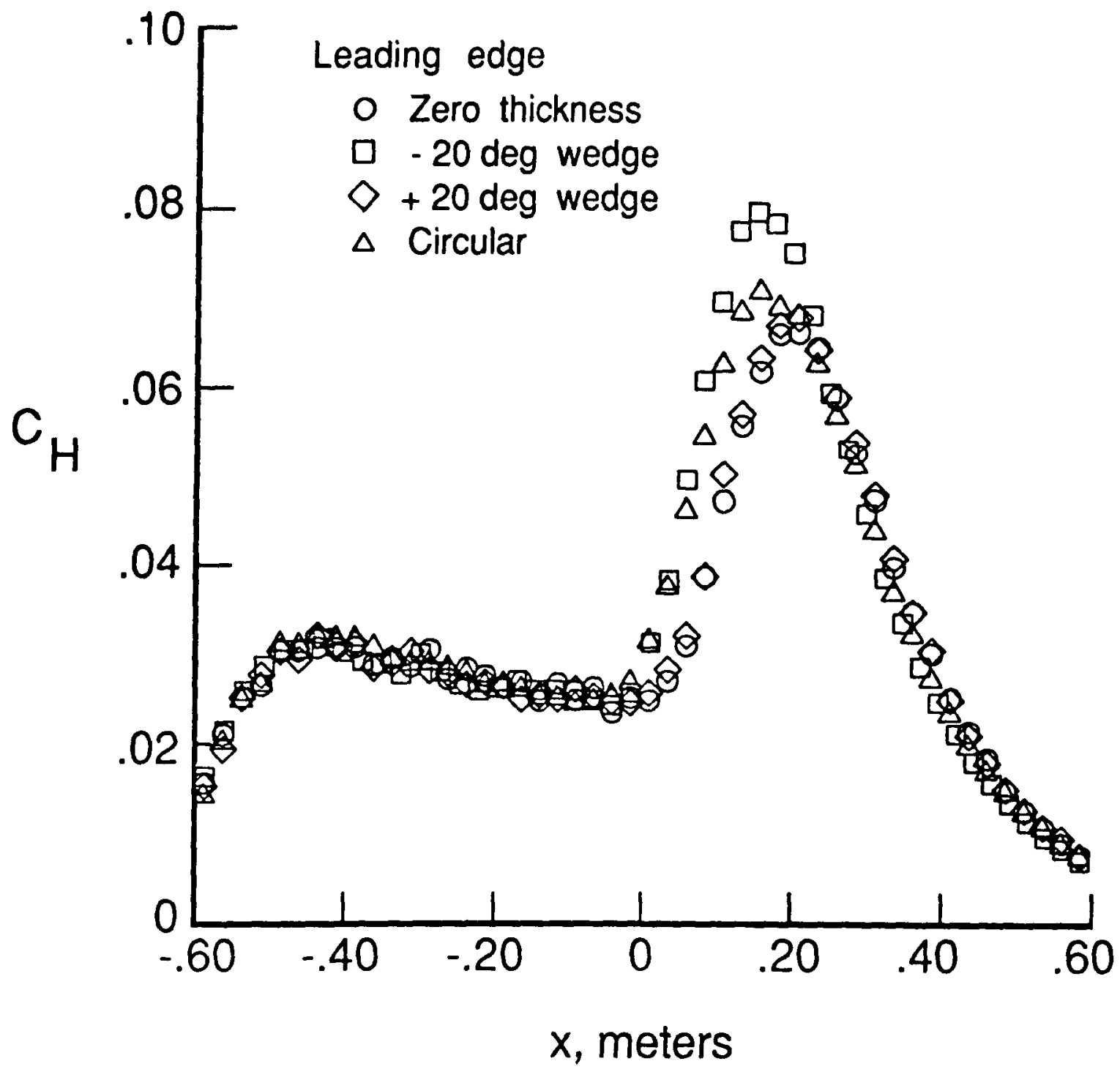

(b) Heat transfer distributions.

Fig. 7 Concluded. 


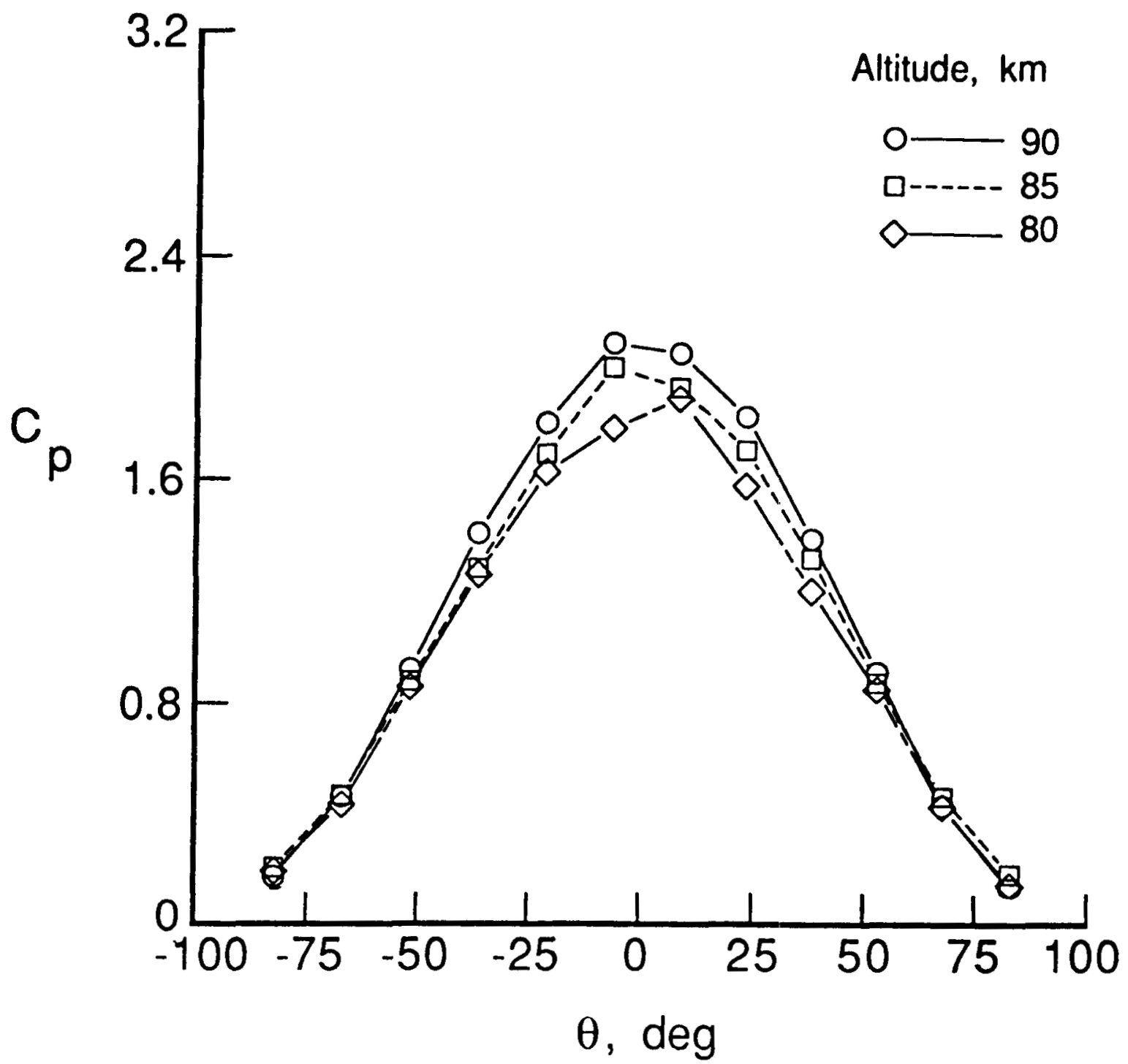

(a) Pressure distributions.

Fig. 8 Isolated blunt leading edge. 


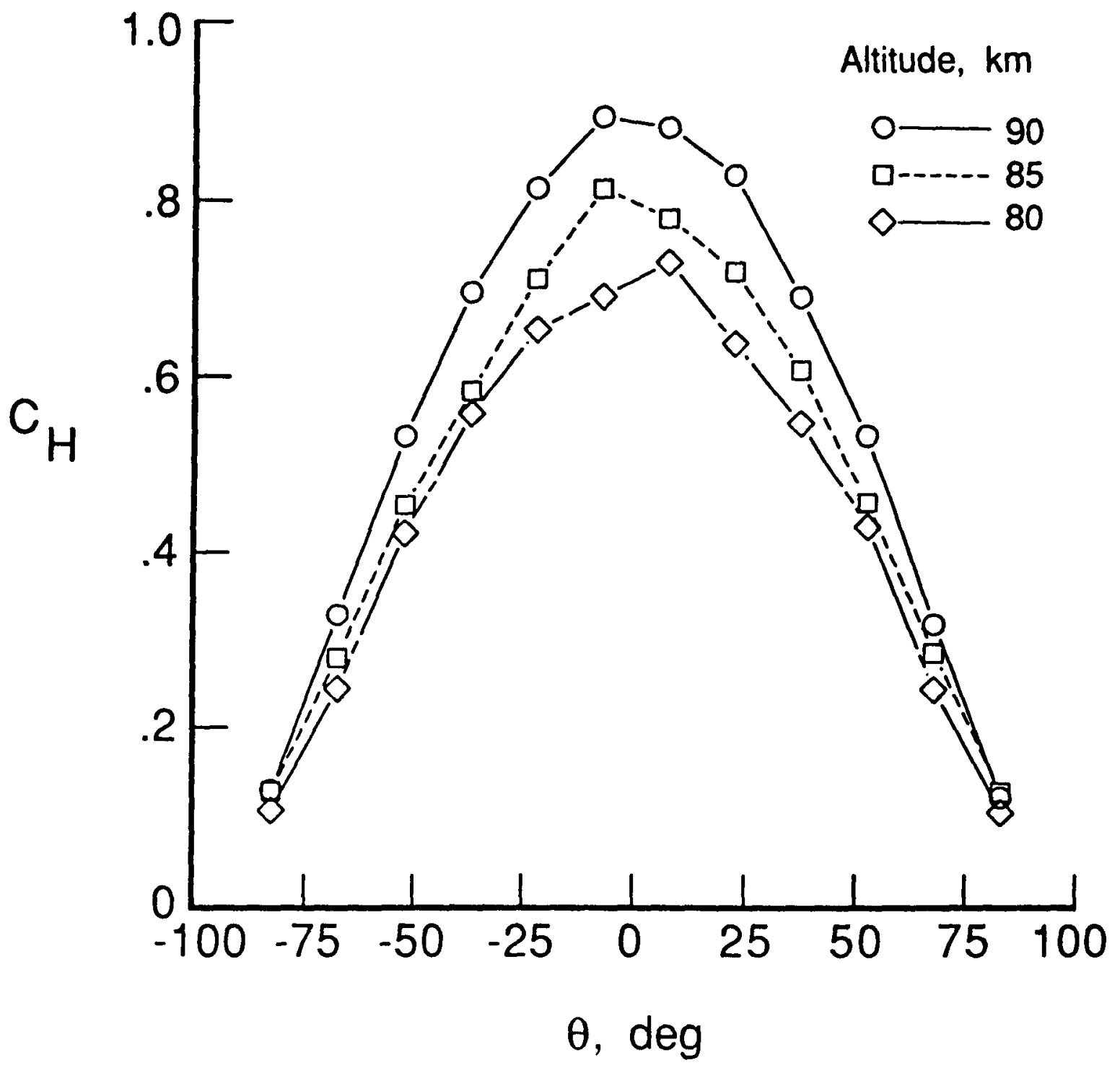

(b) Heat transfer distributions.

Fig. 8 Concluded. 


\section{ORIGINAL PAGR is OF POOR QUALITY}
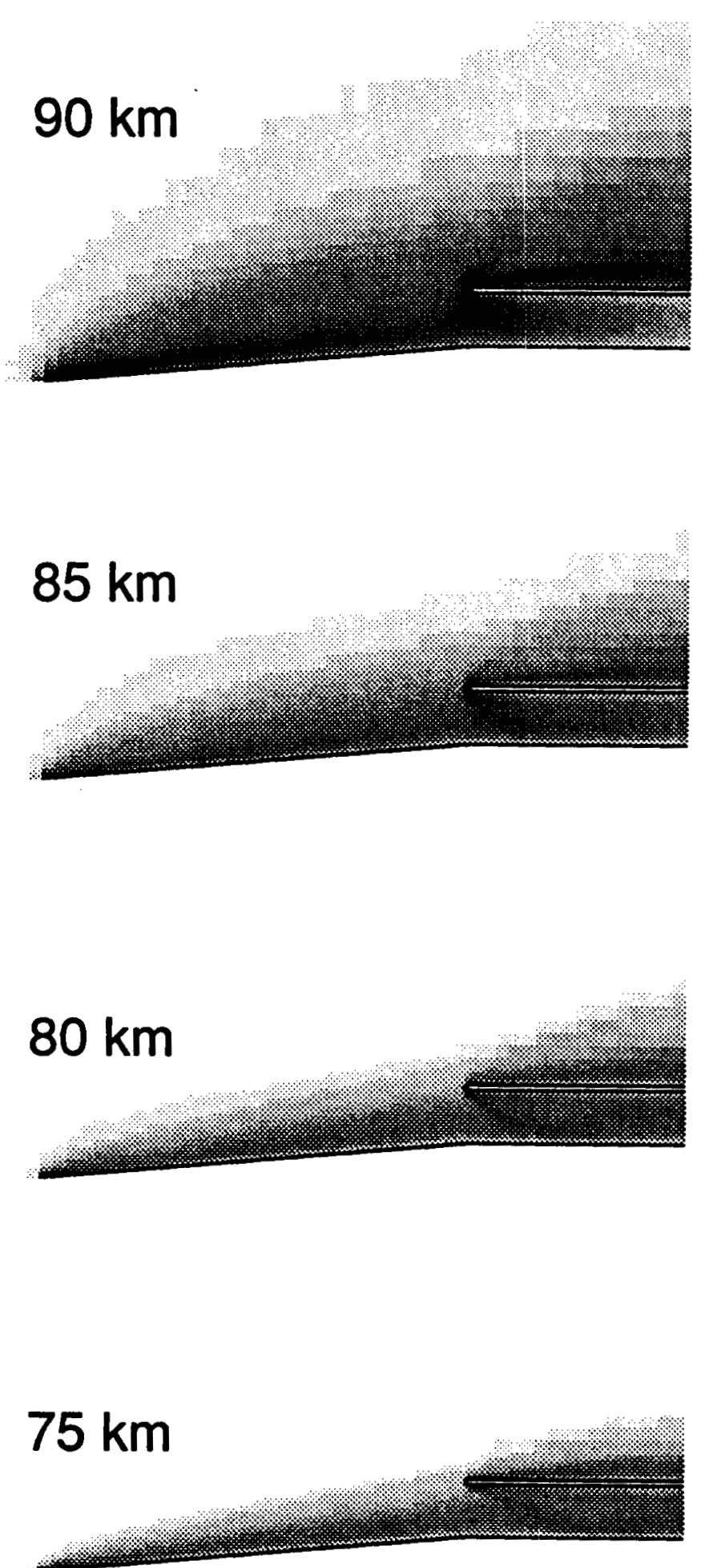

(a) Temperature.

Fig. 9 Gray-shaded contours of flowfleld for 5-degree wedge lower wall. (Darker shades denote higher values.) 

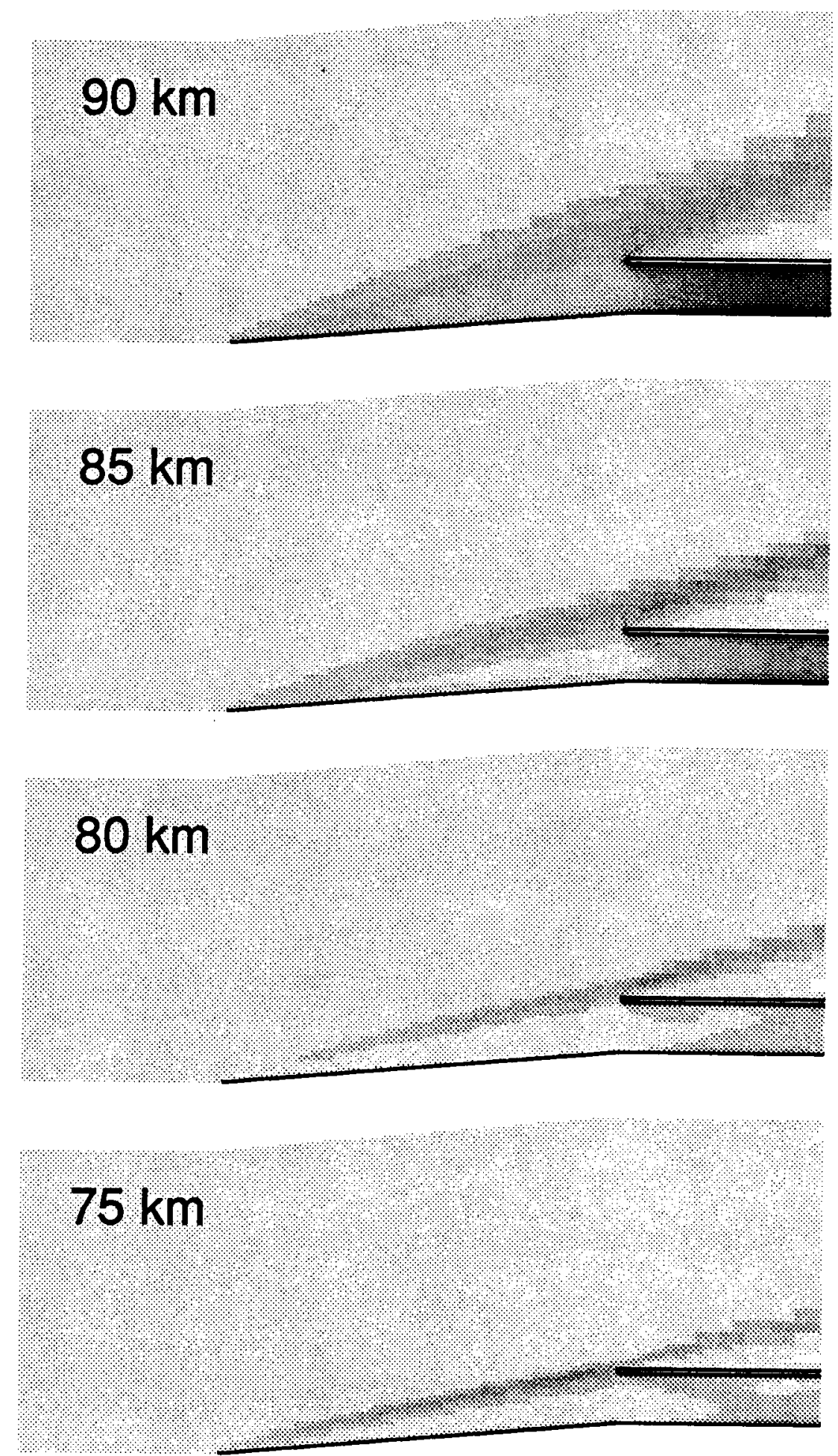

(b) Density.

F1g. 9 Concluded. 


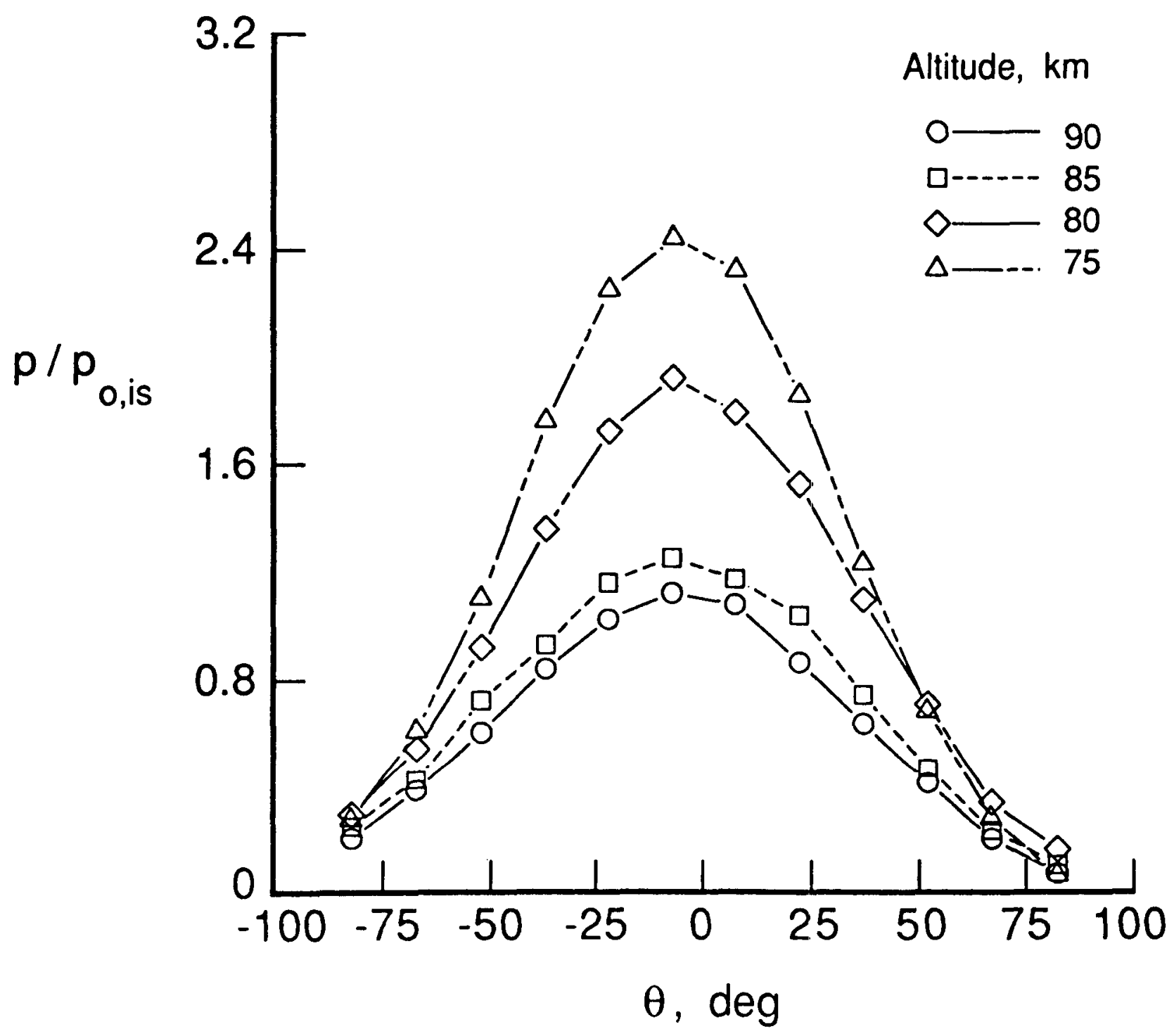

(a) Pressure.

Fig. 10 Interference effects of 5-degree wedge on blunt leading edge. 


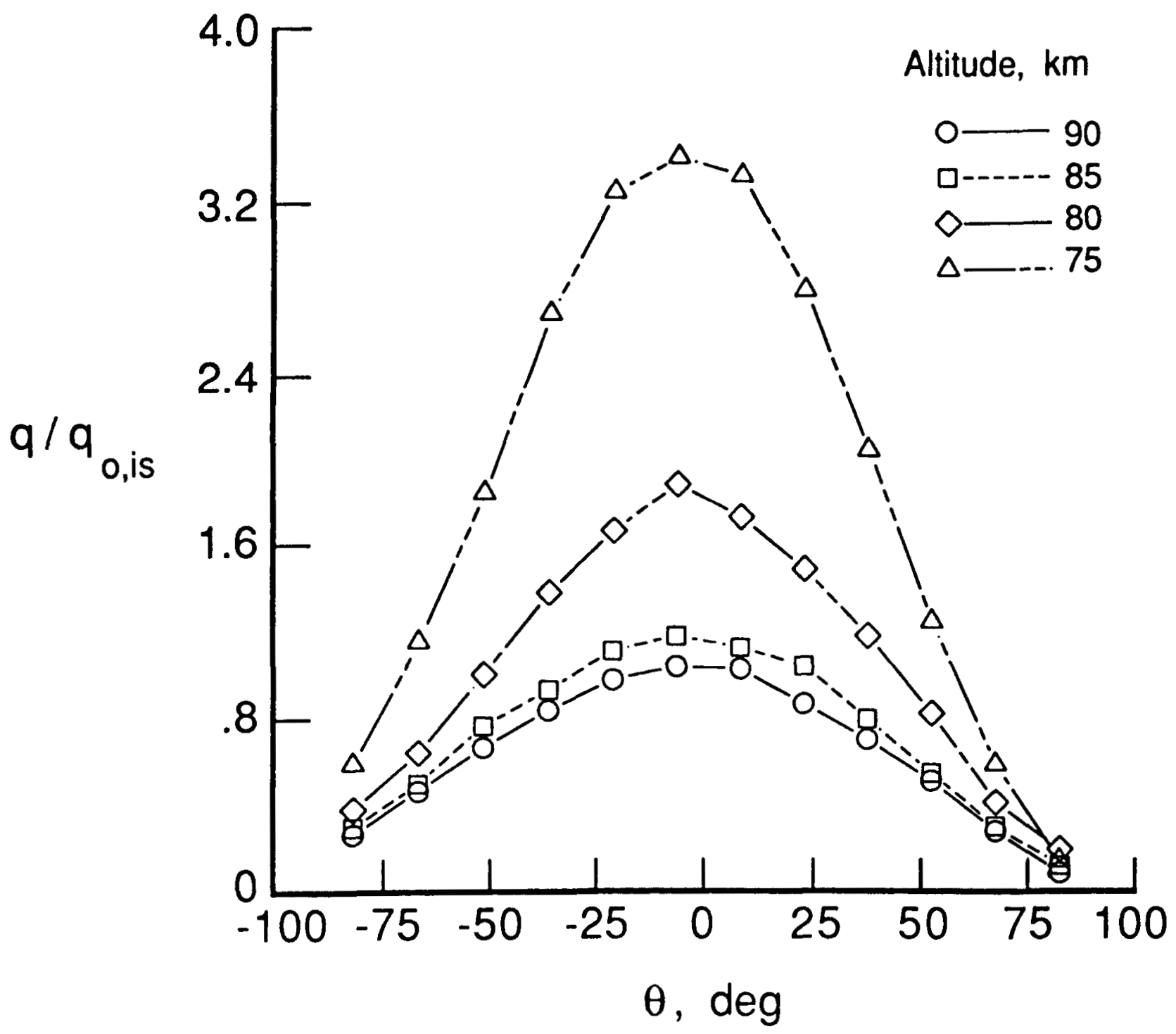

(b) Heat transfer.

Fig. 10 Concluded. 


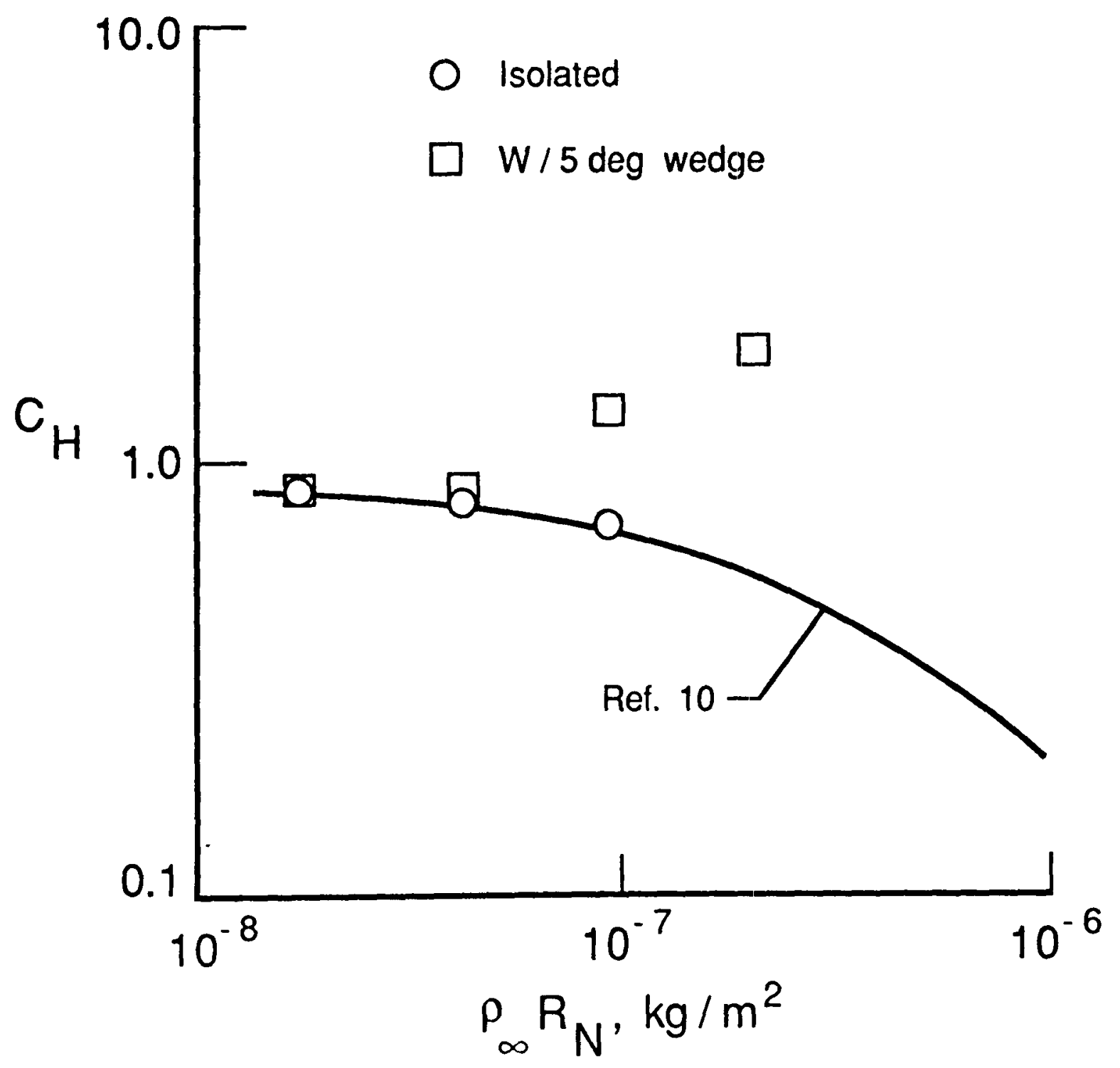

Fig. 11 Stagnation heat transfer on blunt leading edge. 


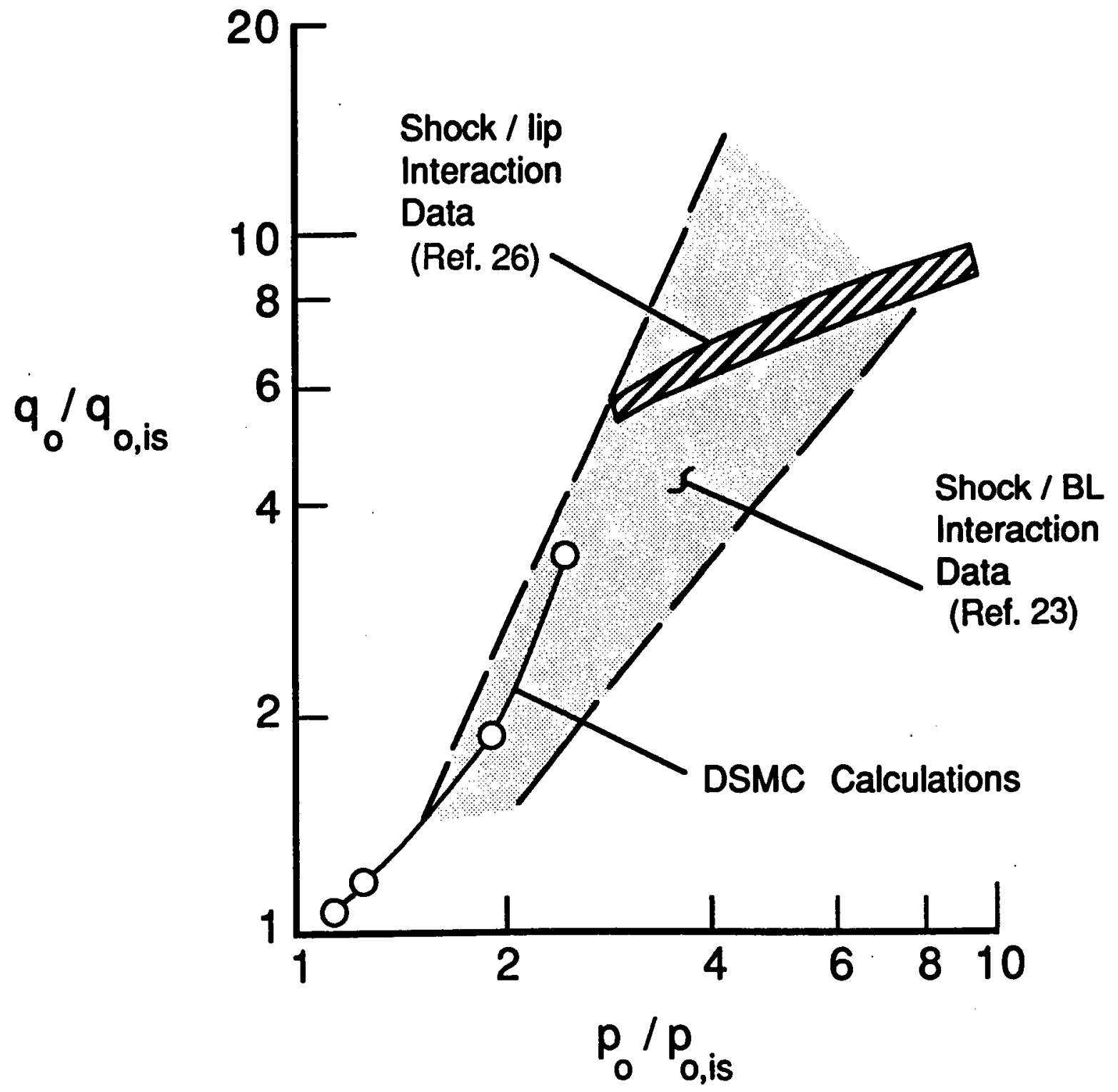

F1g. 12 Correlation of peak heating amplification with pressure amplification. 


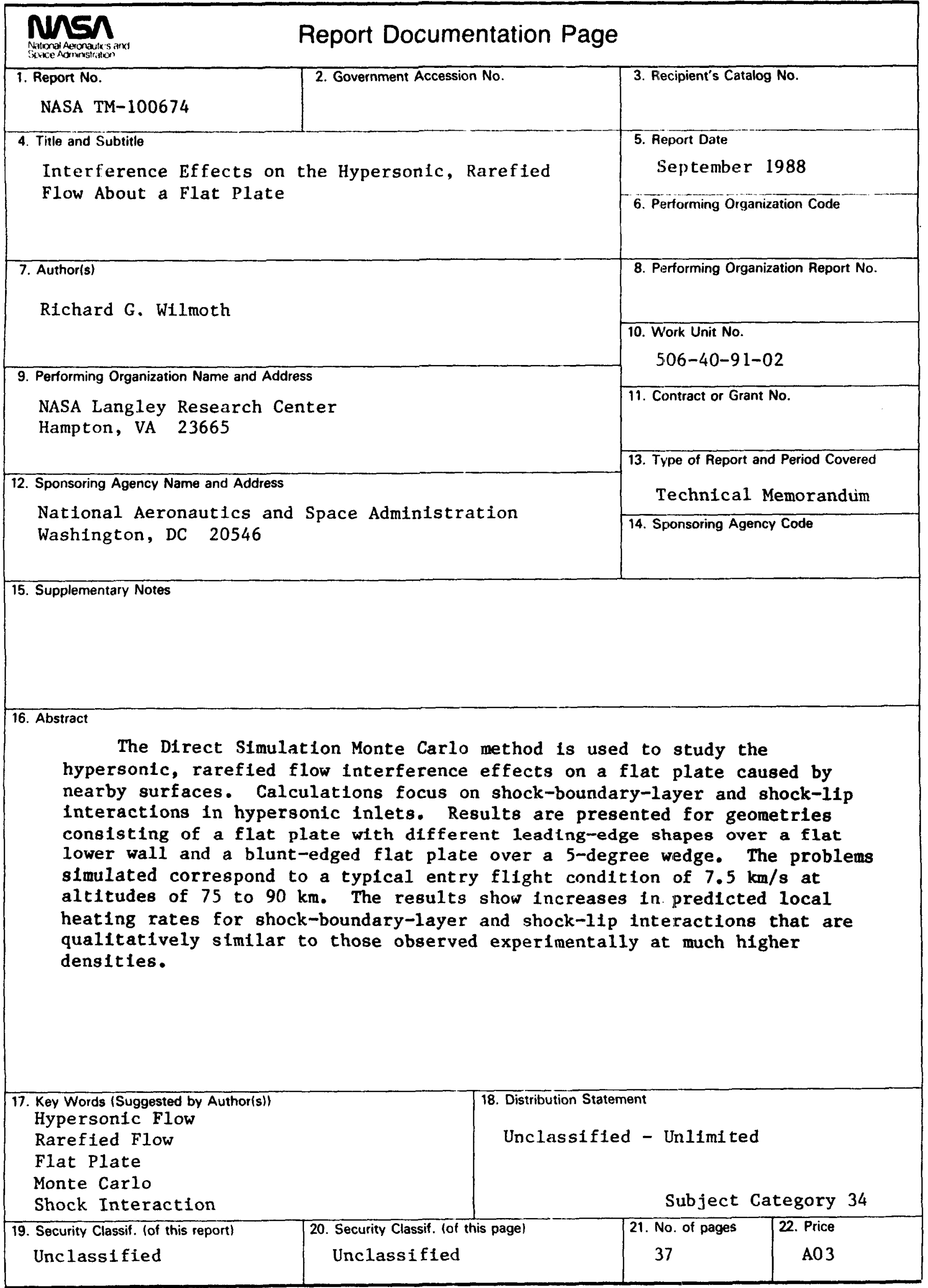

